Article

\title{
Impact of Top Electrodes on the Nonvolatile Resistive Switching Properties of Citrus Thin Films
}

\author{
Kai-Wen Lin, Ting-Yun Wang and Yu-Chi Chang *
}

check for updates

Citation: Lin, K.-W.; Wang, T.-Y.; Chang, Y.-C. Impact of Top Electrodes on the Nonvolatile Resistive Switching Properties of Citrus Thin Films. Polymers 2021, 13, 710 . https://doi.org/10.3390/polym 13050710

Academic Editor: Ben Bin Xu

Received: 26 January 2021

Accepted: 19 February 2021

Published: 26 February 2021

Publisher's Note: MDPI stays neutral with regard to jurisdictional claims in published maps and institutional affiliations.

Copyright: (C) 2021 by the authors Licensee MDPI, Basel, Switzerland. This article is an open access article distributed under the terms and conditions of the Creative Commons Attribution (CC BY) license (https:/ / creativecommons.org/licenses/by/ $4.0 /)$.
Department of Engineering Science, National Cheng Kung University, Tainan 701, Taiwan; kevlin.esc@gmail.com (K.-W.L.); n96094332@gs.ncku.edu.tw (T.-Y.W.)

* Correspondence: christina780712@gmail.com; Tel.: +886-6-275-7575 (ext. 63350)

Abstract: Natural citrus thin films on an indium tin oxide (ITO)/glass substrate were synthesized using the solution method for resistive random access memory (RRAM) applications. The results indicated that the citrus memory device possessed stable resistive switching behavior. For a clear understanding of the role of the interface reaction between the top metal electrode and the citrus film, we investigated the influences of various top electrode (TE) materials on the resistive switching in TE/citrus/ITO devices. In comparison with Au/citrus/ITO and Ti/citrus/ITO devices, the $\mathrm{Al} /$ citrus/ITO device can be reproduced with a DC voltage of more than 100 times while only showing a slight decrease in the ON/OFF ratio. In addition, the Al/citrus/ITO device exhibited a high ON/OFF ratio of over $10^{4}$ and an outstanding uniformity, which was attributed to the fast formation of a native oxide layer $\left(\mathrm{AlO}_{\mathrm{x}}\right)$, as confirmed by the line scan analysis. This indicated that the interface layer, created by the redox reaction between the Al electrode and citrus film, played an important role in the resistive switching properties of TE/citrus/ITO structures. These findings can serve as design guidelines for future bio-based RRAM devices.

Keywords: biodegradability; citrus; resistive memory

\section{Introduction}

With the current rapid economic and technologic growth, the development of consumer goods has resulted in an increase the production of waste electric and electronic equipment. Therefore, electronics consisting of renewable and biodegradable materials are desirable to benefit our living environment [1-4].

The natural material citrus is one of the most popular fruit commodities in the world due to its nutritional values [5]. Citrus is biodegradable, which, in addition to its low toxicity, makes it an ideal candidate for the fabrication of environmentally friendly electronics. As the demand of data storage devices has grown at a prodigious rate, a simple fabrication process, non-volatility, and high-density integration have become basic requirements for modern memory [6,7]. Among various non-volatile memories, resistive random-access memory (RRAM), which is composed of a simple structure, has the superior characteristics of high-speed operation, low power consumption, and a long retention time [8].

For the advanced development of natural material-based RRAM devices, there is an important issue regarding how to optimize memory properties, such as the ON/OFF ratio, endurance, stability, and the dispersions of the resistive switching parameters, which require a clear understanding of the basic mechanism of resistance switching behavior. Currently, many reports have shown that resistive switching properties significantly depend on the metal electrode [9-12]. These reports have indicated that the contacts between the top electrode and insulator layer are related to resistive switching properties [9-12]. The interfacial reaction between the top electrode material and the natural material may cause either a favorable or an adverse influence on the resistive switching properties.

This work emphasized the relationships between the physical properties of citrus thin films and device characteristics. The simple-solution processed citrus RRAM could 
achieve an ON/OFF current ratio of over $10^{4}$. In addition, we also investigated how surface effects may change the electrical properties of citrus memory devices fabricated with various top electrodes. If we can understand the relations between the top electrodes and memory properties of citrus thin films, a stable and high device performance could more effectively be obtained. The memory properties and resistive switching mechanisms of the $\mathrm{Al} /$ citrus/indium tin oxide (ITO) RRAM devices were thoroughly analyzed. RRAM optimization via biomaterial engineering enables a deeper understanding of the material parameters that control the memory properties that are to be better explored for future bio-memory applications.

\section{Materials and Methods}

ITO-coated glass substrates were cut into $2.0 \times 1.5 \mathrm{~cm}^{2}$ pieces and sequentially cleaned with acetone, methanol, and deionized (DI) water in an ultrasonic bath. A citrus solution was prepared using citrus powder mixed with DI water. The citrus concentrations were adjusted to $1.5,1$, and $0.5 \mathrm{mg} / \mathrm{mL}$, which are denoted as $\mathrm{C} 1.5, \mathrm{C} 1$, and $\mathrm{C} 0.5$, respectively. The citrus solution was spun onto the cleaned ITO/glass substrates and baked at $80^{\circ} \mathrm{C}$ for $15 \mathrm{~min}$.

A citrus thin film was then fabricated by spin coating at $5000 \mathrm{rpm}$ for $30 \mathrm{~s}$. Finally, the $\mathrm{Al}$ electrodes with thicknesses of around $120 \mathrm{~nm}$ were deposited on top of the citrus thin film by radio frequency (RF)-magnetron sputtering, using an Ar working pressure of 20 mTorr and an RF power of $250 \mathrm{~W}$. To investigate the electrical properties of C1 thin films with different metals, metal top electrodes (Au and Ti) were deposited by thermal evaporation through a shadow mask. The square-shaped top electrode area was $3 \mathrm{~mm}^{2}$.

Atomic force microscope (AFM) analysis (Dimension ICON with Nano Scope V controller, Bruker, Karlsruhe, Germany) was used to characterize the surface morphology and roughness of the samples. FTIR spectrometry was carried out using a Vertex 80v and Tensor 27 (Bruker) in the range of $4000-800 \mathrm{~cm}^{-1}$.

The electrical properties were characterized by an Agilent B1500 semiconductor parameter analyzer (Santa Clara, CA, USA). To gain further insight into the electrical characteristics, the devices were measured at temperatures ranging from 275 to $393 \mathrm{~K}$ to study the temperature dependence of the current characteristics. TEM analysis was carried out using a $200 \mathrm{kV}$ JEM-2100F Electron Microscope (Jeol, Tokyo, Japan). XPS was carried out using a PHI 5000 Versa Probe (Kanagawa, Japan).

\section{Results}

Figure 1a shows the ON/OFF ratio as a function of the citrus concentration. The ON/OFF ratio significantly decreased with increased citrus concentration up to $1.5 \%$. The high resolution $\mathrm{C} 1 \mathrm{~s}$ spectra of the $\mathrm{C} 0.5, \mathrm{C} 1$, and $\mathrm{C} 1.5$ thin films at the three stages shown in Figure $1 \mathrm{~b}$ were analyzed. The peaks at $284.5,285.7$, and $287.8 \mathrm{eV}$ were attributed to the $\mathrm{C}=\mathrm{C}$ bonds, $s p^{3}$ bulk bonded carbon $\mathrm{C}-\mathrm{C}$ bonds, and $s p^{3}$ bulk bonded $\mathrm{C}=\mathrm{O}$ bonds, respectively [13-15]. The $\mathrm{C}-\mathrm{C} / \mathrm{C}=\mathrm{C}$ ratios were approximately $0.46,0.53$, and 0.4 for the $\mathrm{C} 0.5, \mathrm{C} 1$, and $\mathrm{C} 1.5$ thin films, respectively. After increasing the citrus concentration at $1 \%$, the number of $\mathrm{C}-\mathrm{C} s p^{3}$ bonds increased, producing a low high-resistance state (HRS) current thin film $[16,17]$. The average ON/OFF ratio increased with the number of C-C $s p^{3}$ bonds.

The 2D and 3D AFM topography images of the C0.5, C1, and C1.5 thin films are shown in Figure $1 \mathrm{c}-\mathrm{e}$, respectively. The root-mean-square roughness $\left(\mathrm{R}_{\mathrm{rms}}\right)$ values of the $\mathrm{C} 0.5, \mathrm{C} 1$, and $\mathrm{C} 1.5$ thin films were around $1.52,1.24$, and $1.88 \mathrm{~nm}$, respectively. A suitable citrus concentration enabled the formation of a smooth surface. A lower surface roughness may result in the better uniformity and higher yield of fabricated memory devices [18]. Changes in the citrus content helped tailor the number of functional groups and the surface roughness of the citrus thin films. 


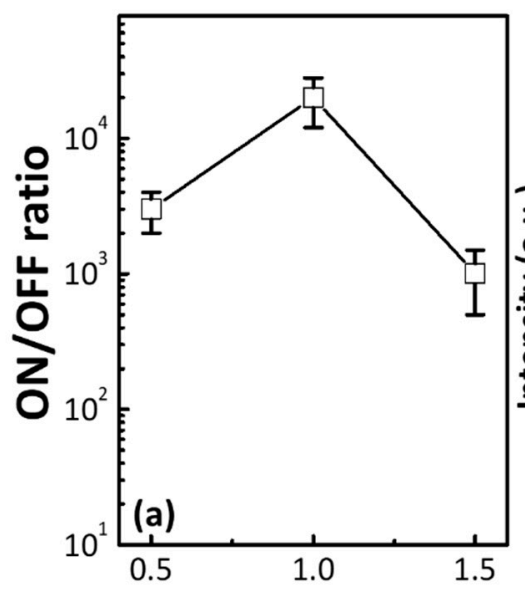

Concentration of citrus (\%)

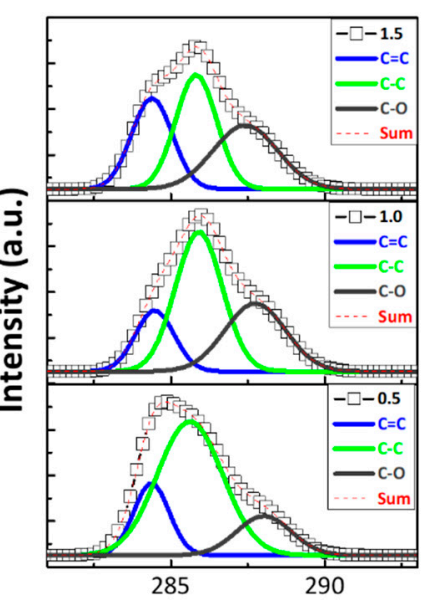

(b) Binding Energy (eV)
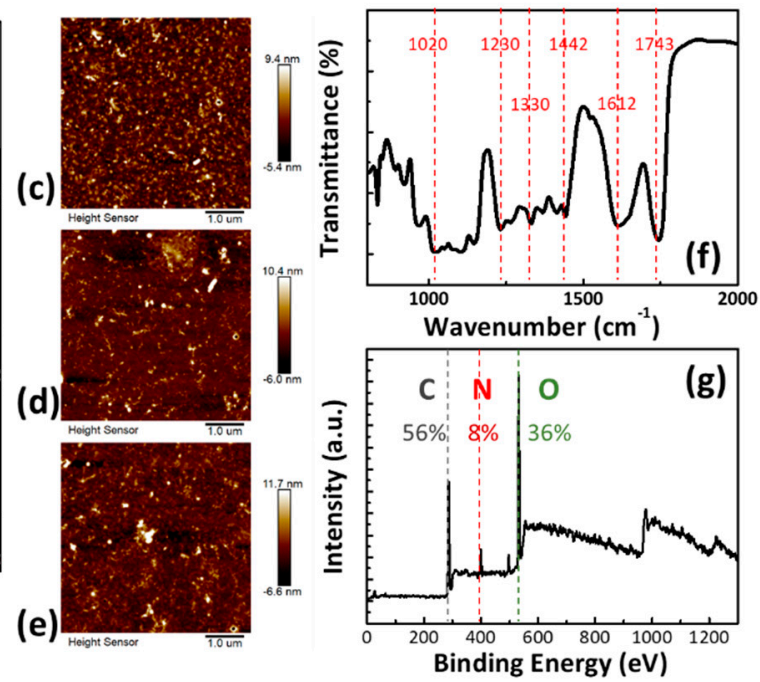

Figure 1. (a) The ON/OFF ratio as a function of the citrus concentration. (b) XPS C 1s spectra of the citrus thin film: C0.5 (bottom), C1 (middle), and C1.5 (top). Tapping mode 2D and 3D AFM topography images of (c) C0.5, (d) C1, and (e) C1.5 thin films. (f) FTIR analysis, and (g) XPS full spectrum analysis of the C1 thin film.

The FTIR spectra of gelatin are shown in Figure 1f. Significant peaks occurred at $1743 \mathrm{~cm}^{-1}$ due to the $\mathrm{C}=\mathrm{O}$ stretching vibrations of carboxylic acid [19]. The absorption bands at 1612 were related to the $-\mathrm{C}(=\mathrm{O})-\mathrm{O}$ stretching of the carboxylate groups and the $\mathrm{C}=\mathrm{O}$ stretching vibrations of carboxylic acid [19].

The peaks occurring at $1330 \mathrm{~cm}^{-1}$ were related to $\mathrm{C}-\mathrm{O}-\mathrm{C}$ stretching of the aryl-alkyl ether linkage [19]. The bands at around $1000-1100 \mathrm{~cm}^{-1}$ could be attributed to $\mathrm{C}-\mathrm{O}-\mathrm{H}$ alcohol bonds of saturated carbon, as well as to $\mathrm{C}-\mathrm{O}$ stretching and $\mathrm{C}-\mathrm{O}$ deformation $[19,20]$. Figure 2a shows the cross-sectional TEM image of the Al/C1/ITO structure. The XPS spectra of the $\mathrm{C} 1$ thin film reveal that the main element in the citrus thin film was carbon-the citrus thin film demonstrated a high carbon signal in the line scan profile (Figure 4d). The thicknesses of the $\mathrm{Al}$ and $\mathrm{C} 1$ thin films were around 120 and $16 \mathrm{~nm}$, respectively. Figure $2 \mathrm{~b}$ depicts the current-voltage $(I-V)$ characteristic of the $\mathrm{C} 1$ memory device. Typical bipolar resistive switching was observed. When the applied voltage ranged from +3 to $-3 \mathrm{~V}$, the ON/OFF ratio of the $\mathrm{C} 1$ memory device was over $10^{5}$. Simultaneously, we plotted the $I-V$ curve of the $\mathrm{C} 1$ memory device on a double log scale to investigate the conduction behaviors. In the negative bias region, there were three distinct regimes. The current at the HRS varied linearly with the voltage in the low-voltage region. Then, a slope of around 2 for $0.2 \mathrm{~V}<\mathrm{V}<0.5 \mathrm{~V}$ and a sharp current increased with a slope of over 2 for $\mathrm{V}>0.5 \mathrm{~V}$. This $I-V$ curve exhibited the characteristics of the trap-controlled space-charge-limited conduction (SCLC) mechanism [21-26]. In the positive bias region, the C1 memory device showed a linear $I-V$ relation, corresponding to the ohmic conduction mechanism. Based on the fitting result, the resistive switching behavior of the $\mathrm{C} 1$ memory device can be explained with the filament conduction mechanism [27-29].

To describe the possible conduction mechanism, the temperature dependencies of the low resistance state (LRS) current at $0.5 \mathrm{~V}$ are summarized in Figure $2 \mathrm{~d}$. The LRS currents of the $\mathrm{C} 1$ memory device increased with the increasing temperature between 273 and $393 \mathrm{~K}$, indicating that the resistive switching material was semiconducting rather than metallic [30]. This suggests that the carbon-rich citrus thin film tended to form conducting filaments containing carbon elements. 

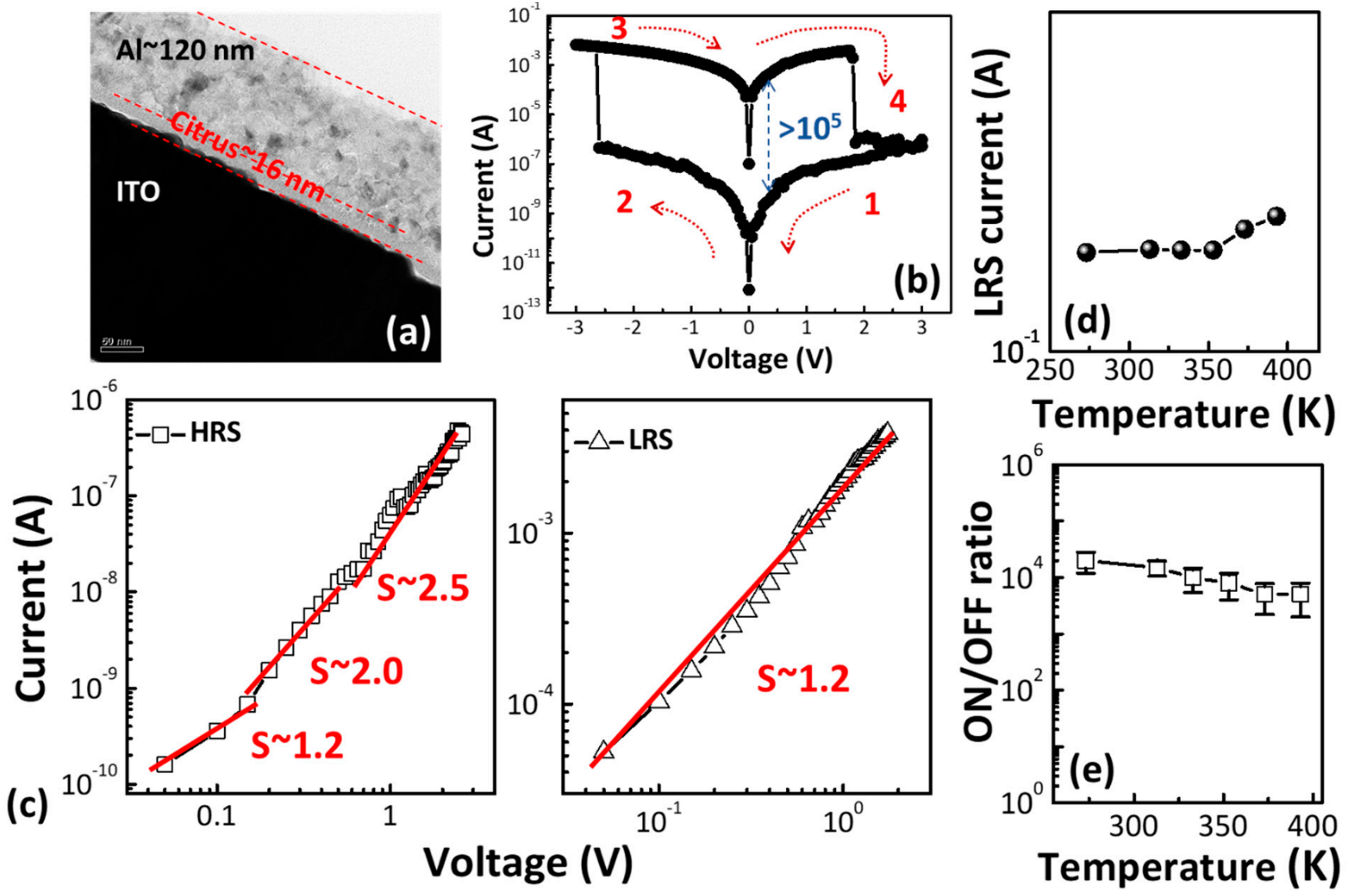

Figure 2. (a) TEM cross-section micrographs and (b) the typical current-voltage ( $I-V$ ) characteristics of the $\mathrm{Al} / \mathrm{C} 1 /$ indium tin oxide (ITO) structure. The bias sweep sequence is indicated by the arrows. (c) Double logarithmic plots of the high resistance state (HRS) (left) and low resistance state (LRS) (right) of the C1 memory device. (d) Temperature dependence of the LRS current of the C1 memory device. (e) The ON/OFF ratio as a function of the temperature from 273 to $393 \mathrm{~K}$.

The ON/OFF ratio as a function of temperature was measured to identify the stability at elevated temperatures of the $\mathrm{C} 1$ memory device, and the results are shown in Figure 2e. The ON/OFF ratio of the $\mathrm{C} 1$ memory device exhibited no significant effects over the temperature range of $273-393 \mathrm{~K}$, indicating its excellent stability at elevated temperatures.

Figure 3a shows the I-V switching cycles of the $\mathrm{C} 1$ memory device. A switching of over 50 cycles was obtained, indicating that the resistive switching behavior is reproducible. The uniformities and stabilities of the $\mathrm{C} 1$ memory device were also measured. Figure $3 \mathrm{~b}$ shows the statistical distribution parameters. The coefficient of variation (CV), defined as the ratio of standard deviation to the average value (AVG), was used to evaluate the distribution. Both the LRS and the HRS currents were measured at $0.1 \mathrm{~V}$. The CV values of $\mathrm{I}_{\mathrm{LRS}}$ and $\mathrm{I}_{\mathrm{HRS}}$ were around 0.5 and 0.8 , respectively. The distribution of the HRS was well-separated from that of the LRS, which provided a good margin of the ON and OFF states in the memory devices.

Figure $3 \mathrm{c}$ shows the retention ability of the $\mathrm{C} 1$ memory device, which was utilized to investigate the stability. The $\mathrm{C} 1$ memory device exhibited an ON/OFF ratio of over $10^{4}$, and no significant decay was observed within $104 \mathrm{~s}$, indicating its excellent data retention capability. Good switching and device uniformity are important factors for bio-memory devices. 

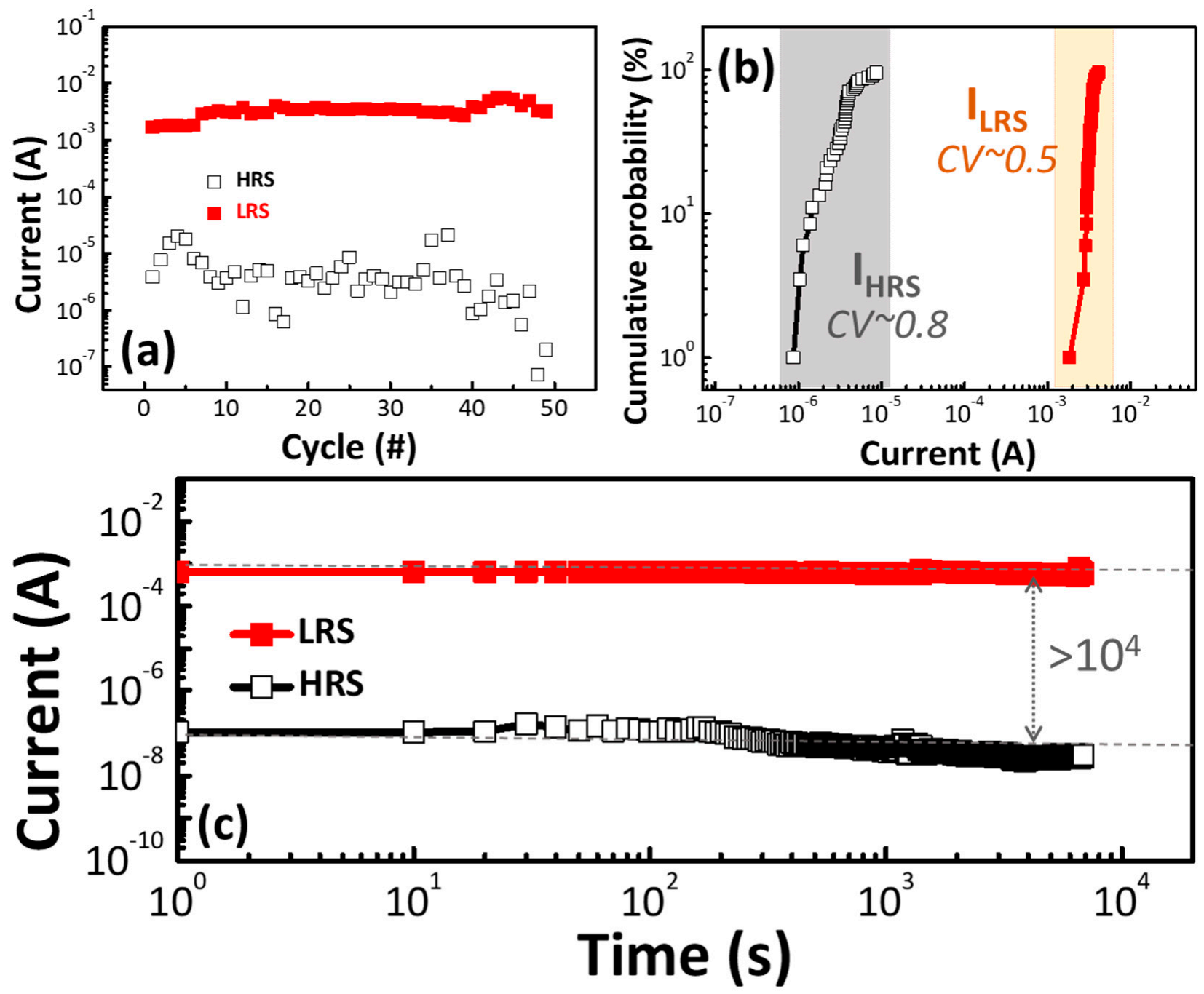

Figure 3. (a) Cycling I-V measurements of the $\mathrm{C} 1$ memory device. (b) The cumulative probability of the HRS and LRS current values for the $\mathrm{C} 1$ memory device under a read bias of $0.1 \mathrm{~V}$. (c) Retention property of the $\mathrm{C} 1$ memory device at room temperature.

The metal/C1/ITO devices were demonstrated to further clarify the switching mechanism of the $\mathrm{C} 1$ memory devices with various top electrodes. Figure 4a shows the ON/OFF ratios of the $\mathrm{C} 1$ memory devices with the top electrodes of $\mathrm{Al}$, $\mathrm{Ti}$, and $\mathrm{Au}$. Due to the lower work function leading to better resistive switching characteristics [9], using $\mathrm{Al}$ or Ti as the top electrodes showed better ON/OFF ratios compared with the Au/C1/ITO structure.

Despite the low work function $(<4 \mathrm{eV})$ of $\mathrm{Ti}$, the $\mathrm{Al} / \mathrm{C} 1 / \mathrm{ITO}$ structure exhibited a better ON/OFF ratio than the Ti/C1/ITO structure did. This result was attributed to the low $\mathrm{HRS}$ current due to the native $\mathrm{AlO}_{\mathrm{x}}$ layer [31-33]. The low-HRS current favored the high ON/OFF ratio.

Figure $4 \mathrm{~b}, \mathrm{c}$ shows the $I-V$ switching cycles of the Ti/C1/ITO and $\mathrm{Au} / \mathrm{C} 1 / \mathrm{ITO}$ structures, respectively. As shown in Figure 4c, the set process occurred in the positive region where the off-state changes to the on-state for bipolar resistive switching. The bipolar resistive switching behavior of the set and the reset voltages were in opposite bias in the $\mathrm{Al}$ or $\mathrm{Ti} / \mathrm{C} 1 / \mathrm{ITO}$ and $\mathrm{Au} / \mathrm{C} 1 / \mathrm{ITO}$ structure, which can be ascribed to the different work functions of top electrodes in the ITO. 

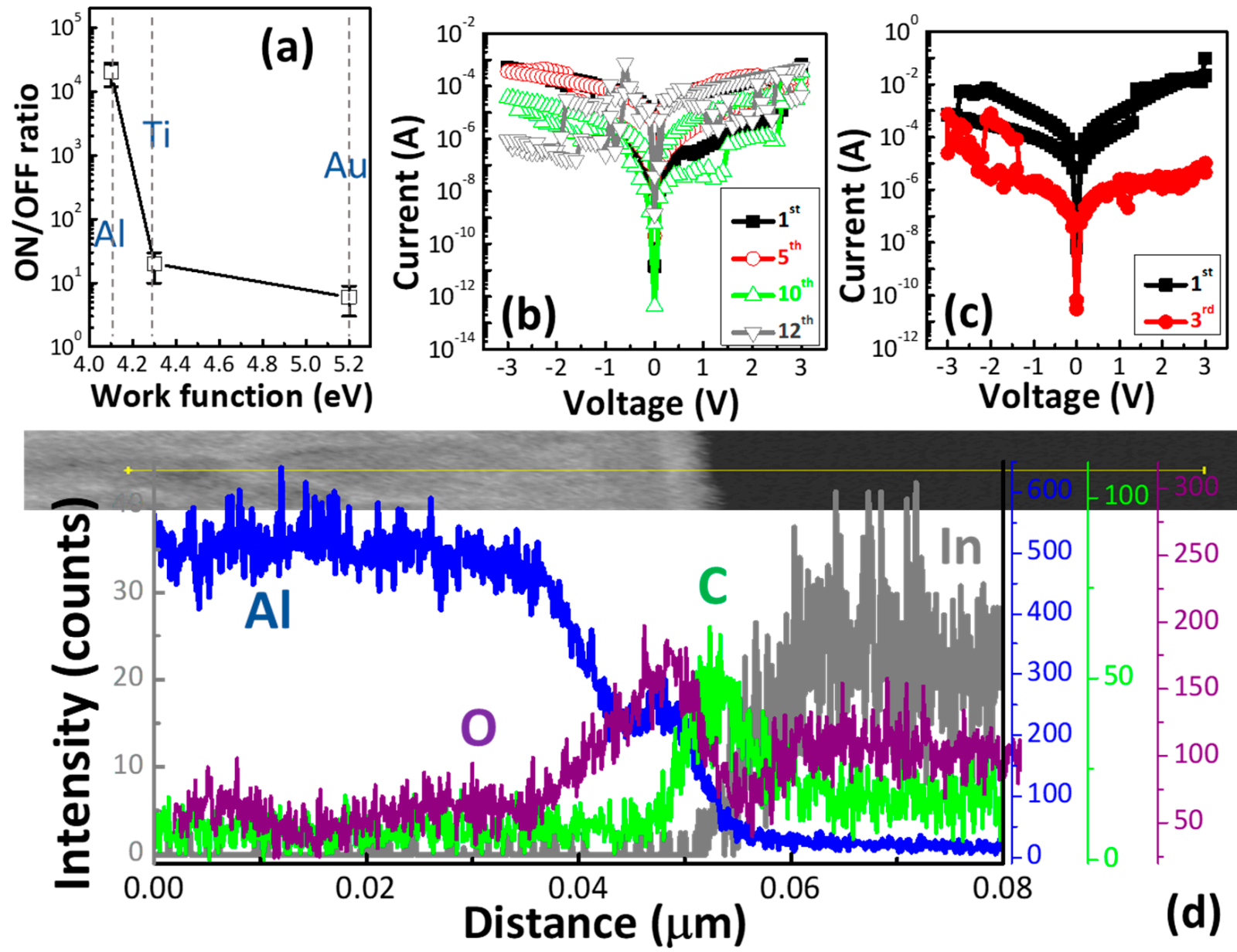

Figure 4. (a) The $\mathrm{ON} / \mathrm{OFF}$ ratio of the $\mathrm{C} 1$ memory devices with various top electrodes. The switching cycles of the (b) $\mathrm{Ti} / \mathrm{C} 1 / \mathrm{ITO}$ and (c) Au/C1/ITO structures. (d) The line-scan profiles along the yellow line marked in the TEM image of the C1 memory device.

Figure $4 \mathrm{~d}$ exhibits the intensities for $\mathrm{Al}, \mathrm{C}, \mathrm{O}$, and In elements as a function of distance. $\mathrm{Al}$ was also detected in the $\mathrm{C} 1$ thin film. The $\mathrm{Al}$ concentration throughout the entire $\mathrm{C} 1$ thin film decreased as the distance increased, indicating that $\mathrm{Al}$ diffused into the $\mathrm{C} 1$ thin film. The $\mathrm{AlO}_{x}$ layer between the $\mathrm{Al}$ electrode and the $\mathrm{C} 1$ thin film was detected. According to the line-scan profile of the $\mathrm{C} 1$ memory device, the $\mathrm{AlO}_{x}$ at the $\mathrm{Al} / \mathrm{C} 1$ interface consisted mostly of $\mathrm{Al}$ and $\mathrm{O}$. The formation of the $\mathrm{AlO}_{\mathrm{x}}$ layer enabled the enhancement of the $\mathrm{ON} / \mathrm{OFF}$ ratio of the $\mathrm{C} 1$ memory device. A good ON/OFF ratio is greatly needed for practical applications of resistive memory. These results thus support the strong role of the top electrode (TE) materials in dictating the switching and stability of resistive memory devices.

\section{Conclusions}

In summary, we investigated citrus thin films as a resistive layer in memory devices, as well as the influence of top electrodes on device performance. The citrus-based RRAM made with $\mathrm{Al}$ electrodes possessed an outstanding ON/OFF ratio of over $10^{4}$. An ON/OFF ratio of less than $10^{1}$ was found in $\mathrm{Au} /$ citrus/ITO RRAMs. In addition to the relatively high $\mathrm{ON} / \mathrm{OFF}$ ratio, the $\mathrm{Al} /$ citrus/ITO RRAM also exhibited an acceptable uniformity, a stable switching cycle, and an outstanding stability at elevated temperatures compared with the $\mathrm{Ti} /$ citrus/ITO RRAMs. We attribute the better memory properties of the Al/citrus/ITO RRAM to the fast formation of a native oxide layer $\left(\mathrm{AlO}_{\mathrm{x}}\right)$, as confirmed by the line scan analysis. The bipolar resistive switching behavior of the set and reset voltages was in the opposite bias in the $\mathrm{Al} /$ citrus/ITO and Au/citrus/ITO RRAMs, which can be ascribed to 
the different work functions of the top electrodes in the ITO. The analysis of the temperaturedependent LRS current and fitting results indicated that the resistive switching behavior of the $\mathrm{C} 1$ memory device was related to the formation of filaments containing carbon elements. These findings allow for RRAM optimization via biomaterial engineering to be better explored in future bio-memory applications.

Author Contributions: K.-W.L. designed the experiment and assisted in the data analysis. T.Y.W. fabricated the devices and the samples for the electrical and physical measurements. Y.-C.C. conceived and supervised the project. All authors have read and agreed to the published version of the manuscript.

Funding: This research is sponsored by the Ministry of Science and Technology of Taiwan under Grant no. MOST 108-2636-E-006-008.

Data Availability Statement: We have no depository of publicly archived datasets analyzed or generated during the study. Data are available on request; contact please authors at their e-mail addresses.

Acknowledgments: We thank Jui-Chin Lee (Instrument Center NCKU) for the sample preparation and XPS investigation.

Conflicts of Interest: The authors declare no conflict of interest.

\section{References}

1. Xu, B.; Chen, D.; Hayward, R.C. Mechanically gated electrical switches by creasing of patterned metal/elastomer bilayer films. Adv. Mater. 2014, 26, 4381-4385. [CrossRef] [PubMed]

2. Hayward, R.C.; Chen, D.; Xu, B. Mechanically gated electrical switches by creasing of patterned metal/elastomer bilayer films. U.S. Patent No. 10,138,542, 27 November 2018.

3. Wang, C.; Xu, B.B.; Terry, J.G.; Smith, S.; Walton, A.J.; Wang, S.; Lv, H.; Li, Y. Flexible, strain gated logic transducer arrays enabled by initializing surface instability on elastic bilayers. APL Mater. 2019, 7, 031509. [CrossRef]

4. Lu, H.; Lei, M.; Zhao, C.; Xu, B.; Leng, J.; Fu, Y.Q. Structural design of flexible Au electrode to enable shape memory polymer for electrical actuation. Smart Mater. Struct. 2015, 24, 045015. [CrossRef]

5. Cao, W.; Liu, C.; Jia, P. Feature Extraction and Classification of Citrus Juice by Using an Enhanced L-KSVD on Data Obtained from Electronic Nose. Sensors 2019, 19, 916. [CrossRef]

6. Zhao, W.; Belhaire, E.; Chappert, C.; Mazoyer, P. Power and area optimization for run-time reconfiguration system on programmable chip based on magnetic random access memory. IEEE Trans. Magn. 2009, 45, 776-780. [CrossRef]

7. Wang, W. Magnetic random accessible memory based magnetic content addressable memory cell design. IEEE Trans. Magn. 2010, 46, 1967-1970. [CrossRef]

8. Lee, M.J.; Park, Y.; Suh, D.S.; Lee, E.H.; Seo, S.; Kim, D.C.; Jung, R.; Kang, B.S.; Ahn, S.E.; Lee, C.B.; et al. Two series oxide resistors applicable to high speed and high density nonvolatile memory. Adv. Mater. 2007, 19, 3919-3923. [CrossRef]

9. Lin, C.-Y.; Wu, C.-Y.; Wu, C.-Y.; Lee, T.-C.; Yang, F.-L.; Hu, C.; Tseng, T.-Y. Effect of Top Electrode Material on Resistive Switching Properties of $\mathrm{ZrO}_{2}$ Film Memory Devices. IEEE Electron Device Lett. 2007, 28, 366-368. [CrossRef]

10. Ambrosi, E.; Bricalli, A.; Laudato, M.; Ielmini, D. Impact of oxide and electrode materials on the switching characteristics of oxide ReRAM devices. Faraday Discuss. 2019, 213, 87-98. [CrossRef]

11. Lin, C.-C.; Chang, Y.P.; Ho, C.-C.; Shen, Y.-S.; Chiou, B.-S. Effect of Top Electrode Materials on the Nonvolatile Resistive Switching Characteristics of CCTO Films. IEEE Trans. Magn. 2011, 47, 633-636. [CrossRef]

12. Ke, J.-J.; Wei, T.-C.; Tsai, D.-S.; Lin, C.-H.; He, J.-H. Surface effects of electrode-dependent switching behavior of resistive random-access memory. Appl. Phys. Lett. 2016, 109, 131603. [CrossRef]

13. Si, W.; Lei, W.; Han, Z.; Zhang, Y.; Hao, Q.; Xia, M. Electrochemical sensing of acetaminophen based on poly(3,4ethylenedioxythiophene)/graphene ox- ide composites. Sensors Actuators B Chem. 2014, 193, 823-829. [CrossRef]

14. Chua, C.K.; Ambrosi, A.; Pumera, M. Graphene oxide reduction by standard industrial reducing agent: Thiourea dioxide. J. Mater. Chem. 2012, 22, 11054. [CrossRef]

15. Moon, I.K.; Lee, J.; Ruoff, R.S.; Lee, H. Reduced graphene oxide by chemical graphitization. Nat. Commun. 2010, 1, 73. [CrossRef]

16. Chang, Y.C.; Jian, J.C.; Hsu, Y.L.; Huang, W.Y.; Young, S.J. A Green Strategy for Developing a Self-Healing Gelatin Resistive Memory Device. ACS Appl. Polym. Mater. 2020, 11, 5318-5326. [CrossRef]

17. Chang, Y.C.; Lee, C.J.; Wang, L.W.; Wang, Y.H. Highly Uniform Resistive Switching Properties of Solution-Processed SilverEmbedded Gelatin Thin Film. Small 2018, 13, 1703888. [CrossRef]

18. Hwang, Y.H.; An, H.M.; Cho, W.J. Performance Improvement of the Resistive Memory Properties of InGaZnO Thin Films by Using Microwave Irradiation. Jpn. J. Appl. Phys. 2014, 53, 04EJ04. [CrossRef] 
19. Aburtoa, J.; Morana, M.; Galanob, A.; Torres-Garcíaa, E. Non-isothermal pyrolysis of pectin: A thermochemical and kinetic approach. J. Anal. Appl. Pyrolysis 2015, 112, 94-104. [CrossRef]

20. Yang, H.; Yan, R.; Chen, H.; Lee, H.D.; Zheng, C. Characteristics of hemicellulose, cellulose and lignin pyrolysis. Fuel 2007, 86, 1781-1788. [CrossRef]

21. Lampert, M.A. Simplified Theory of Space-Charge-Limited Currents in an Insulator with Traps. Phys. Rev. 1956, 103, 1648-1656. [CrossRef]

22. Yang, Y.C.; Pan, F.; Zeng, F.; Liu, M. Switching mechanism transition induced by annealing treatment in nonvolatile $\mathrm{Cu} / \mathrm{ZnO} / \mathrm{Cu} / \mathrm{ZnO} / \mathrm{Pt}$ resistive memory: From carrier trapping/detrapping to electrochemical metallization. J. Appl. Phys. 2009, 106, 123705. [CrossRef]

23. Shi, T.; Yang, R.; Guo, X. Coexistence of analog and digital resistive switching in $\mathrm{BiFeO}_{3}$-based memristive devices. Solid State Ion. 2016, 296, 114-119. [CrossRef]

24. Zhu, Y.; Li, M.; Liu, J.; Hu, Z.; Wang, Q.; Zhang, Y.; Wei, M.; Hu, C. Resistive switching behavior in Pt/YSZ/Nb:SrTiO 3 heterostructure for nonvolatile multilevel memories. J. Alloy. Compd. 2014, 612, 30-33. [CrossRef]

25. Zhu, Y.; Li, M.; Zhou, H.; Hu, Z.; Liu, X.; Liao, H. Improved bipolar resistive switching properties in $\mathrm{CeO}_{2} / \mathrm{ZnO}$ stacked hetero-structures. Semicond. Sci. Technol. 2013, 28, 015023. [CrossRef]

26. Zhu, Y.; Li, M.; Zhou, H.; Hu, Z.; Liu, X.; Fang, X.; Sebo, B.; Fang, G.; Zhao, X. Nonvolatile bipolar resistive switching in an $\mathrm{Ag} / \mathrm{TiO} 2 / \mathrm{Nb}: \mathrm{SrTiO}_{3} /$ In device. J. Phys. D Appl. Phys. 2012, 45, 375303. [CrossRef]

27. Wang, Z.S.; Zeng, F.; Yang, J.; Chen, C.; Yang, Y.C.; Pan, F. Reproducible and Controllable Organic Resistive Memory Based on Al/Poly(3,4-ethylene-dioxythiophene):Poly(styrenesulfonate)/Al Structure. Appl. Phys. Lett. 2010, 97, 253301. [CrossRef]

28. Chang, Y.C.; Xue, R.Y.; Wang, Y.H. Multilayered Barium Titanate Thin Films by Sol-Gel Method for Nonvolatile Memory Application. Ieee Trans. Electron Devices 2014, 61, 4090-4097. [CrossRef]

29. Chang, Y.C.; Wang, Y.H. Resistive Switching Behavior in Gelatin Thin Films for Nonvolatile Memory Application. ACS Appl. Mater. Interfaces 2014, 6, 5413-5421. [CrossRef] [PubMed]

30. Luo, W.C.; Hou, T.H.; Lin, K.L.; Lee, Y.J.; Lei, T.F. Reversible Transition of Resistive Switching Induced by Oxygen-Vacancy and Metal Filaments in $\mathrm{HfO}_{2}$. Solid-State Electron. 2013, 89, 167-170. [CrossRef]

31. Kumari, N.; Pandey, M.; Hamada, K.; Hirotani, D.; Nagamatsu, S.; Hayase, S.; Pandey, S.S. Role of Device Architecture and $\mathrm{AlO}_{\mathrm{x}}$ Interlayer in Organic Schottky Diodes and Their Interpretation by Analytical Modeling. J. Appl. Phys. 2019, $126,125501$. [CrossRef]

32. Chang, Y.C.; Jian, J.C.; Chuang, M.Y.; Hsu, Y.L.; Huang, W.Y.; Young, S.J. Metal and Carbon Filaments in Bio-memory Device through Controlled the Al/Apple Pectin Interface. ACS Appl. Electron. Mater. 2020, 2, 2798-2805. [CrossRef]

33. Chang, Y.C.; Jian, J.C.; Hsu, Y.L.; Huang, W.Y.; Chen, Z.C.; Liu, K.M. “Repeatable room-temperature self-healing memory device based on gelatin films. Flex. Print. Electron. 2020, 5, 045005. [CrossRef] 